\title{
碳掺杂 $\mathrm{TiO}_{2}$ 纳米管电极的简易制备及其光电化学性能
}

\author{
赵鹏, 李忠, 崔晓莉 \\ (复旦大学 材料科学系, 上海 200433)
}

摘 要: 通过阳极氧化方法制备了 $\mathrm{TiO}_{2}$ 纳米管薄膜, 在 $\mathrm{NaHCO}_{3}$ 存在下对该薄膜进行热处理得到碳掺杂 $\mathrm{TiO}_{2}\left(\mathrm{C}-\mathrm{TiO}_{2}\right)$ 纳米管薄膜, 通过 $\mathrm{X}$ 射线衍射仪 $(\mathrm{XRD}) 、$ 扫描电子显微镜( $\left.\mathrm{SEM}\right) 、 \mathrm{X}$ 射线光电子能谱 $(\mathrm{XPS})$ 、紫外-可 见漫反射光谱、电化学阻抗谱(EIS)和 Mott-Schottky 等方法对得到的薄膜进行表征。XRD 结果表明 $\mathrm{C}^{-} \mathrm{TiO}_{2}$ 纳米管 薄膜中的 $\mathrm{TiO}_{2}$ 主要为锐钠矿晶型; $\mathrm{SEM}$ 结果显示薄膜存在纳米管结构; XPS 分析表明 $\mathrm{C}-\mathrm{TiO}_{2}$ 纳米管薄膜中的 $\mathrm{C}$ 以 替代型掺杂形式进入到 $\mathrm{TiO}_{2}$ 晶格中; 光电化学性能测试显示, 相对于 $\mathrm{TiO}_{2}$ 纳米薄膜, $\mathrm{C}-\mathrm{TiO}_{2}$ 阻抗减小, 平带电位由 $-0.28 \mathrm{~V}$ 负移至 $-0.38 \mathrm{~V}$, 具有更好的紫外-可见光和可见光响应, 紫外-可见光下的光电流是未掺杂的 1.7 倍。利用 阳极氧化的 $\mathrm{Ti}$ 丝作为光阳极和 Pt 丝作为对电极组装了染料敏化太阳能电池并进行了性能测试, 结果表明, 经过碳 掺杂的 $\mathrm{Ti} / \mathrm{TiO}_{2}$ 丝为光阳极电池的短路电流密度和电池效率分别达到 $0.17 \mathrm{~mA} / \mathrm{cm}^{2}$ 和 $3.8 \%$, 较未掺杂的 $\mathrm{Ti} / \mathrm{TiO}_{2}$ 丝 为光阳极的电池的短路电流密度和电池效率均增大, 表明适量的碳掺杂有利于提高电池效率。

关 键 词: $\mathrm{TiO}_{2}$; 阳极氧化; $\mathrm{C}$ 掺杂; 光电化学

中图分类号: 0644 文献标识码: A

\section{Facile Preparation Carbon-Doped $\mathrm{TiO}_{2}$ Nanotube Electrodes and Its Enhanced Photoelectrochemical Response}

\author{
ZHAO Peng, LI Zhong, CUI Xiao-Li \\ (Department of Materials Science, Fudan University, Shanghai 200433, China)
}

\begin{abstract}
Nanostructured carbon-doped titanium dioxide were fabricated by thermal treatment of anodized titanium dioxide nanotube with the presence of $\mathrm{NaHCO}_{3}$. The resulted samples were characterized via X-ray diffraction, scanning electron microscopy, X-ray photoelectron spectroscopy, UV-Vis diffuse reflectance spectra, electrochemical impedance spectroscopy and photoelectrochemistry methods. Anatase type $\mathrm{TiO}_{2}$ nanotubes and almost no influence from $\mathrm{C}$ doping were observed from XRD and SEM results. XPS spectra showed that the $\mathrm{O}$ was partly replaced by $\mathrm{C}$ in the resulted carbon-doped titanium dioxide nanotubes. Enhanced photocurrents were identified for the $\mathrm{C}_{-} \mathrm{TiO}_{2}$ nanotube and 1.7 times was observed in comparison to the $\mathrm{TiO}_{2}$. Electrochemical impedance spectroscopy indicates the decrease of charge transfer resistance and flat band potential also negative shift from $-0.28 \mathrm{~V}$ to $-0.38 \mathrm{~V}$. Needle- shaped dye sensitized solar cells were developed by using anodized Ti and Pt wire. Improved photovoltaic performance was demonstrated by the photocurrent density-photovoltage curves for DSSCs when the anodized Ti wire was thermal treated with the presence of $\mathrm{NaHCO}_{3}$. The short-circuit current and energy conversion efficiency were up to $0.17 \mathrm{~mA} / \mathrm{cm}^{2}$ and $3.8 \%$, respectively.
\end{abstract}

收稿日期: 2014-11-13; 收到修改稿日期：2015-01-09

基金项目：国家自然科学基金(21273047); 国家 “973”计划项目(2011CB933300)

National Natural Science Foundation of China (21273047); 973 Programm (2011CB933300)

作者简介: 赵 鹏(1987-), 男, 硕士研究生. E-mail: 12210300053@fudan.edu.cn

通讯作者: 崔晓莉, 教授. E-mail: xiaolicui@fudan.edu.cn 
Key words: $\mathrm{TiO}_{2}$; anodic oxidation; carbon doping; photoelectrochemistry

二氧化钛半导体具有化学性质稳定、光催化氧 化活性高、无毒和价格低廉等优点, 在染料敏化太 阳能电池、光解水产氢气和光催化降解有机污染物 等领域有着广泛的应用前景 ${ }^{[1-2]}$ 。但它的禁带宽度 较大 $(3.0 \sim 3.2 \mathrm{eV})$, 只能吸收占太阳光中能量的 $3 \% \sim 5 \%$ 的紫外光, 对太阳能的利用率较低 ${ }^{[3]}$, 因 此开发具有高活性的可见光响应的 $\mathrm{TiO}_{2}$ 光催化剂 十分必要。提高二氧化钛光催化性能的主要途径 有金属、非金属离子的掺杂，元素共掺杂等。已有 的研究表明, 通过向二氧化钛掺入非金属元素, 例 如碳 ${ }^{[4-5] \text { 、氮 }}{ }^{[6]}$ 或碳氮共掺杂 ${ }^{[7]}$ 等可以提高二氧化钛 的光催化效率。

碳掺杂能减小 $\mathrm{TiO}_{2}$ 禁带宽度, 从而提高它的光 催化性能。Khan 等 ${ }^{[8]}$ 利用钛片在天然气火焰中热解 合成了化学改性的碳掺杂的 $\mathrm{TiO}_{2}$, 实验表明改性 $\mathrm{TiO}_{2}$ 膜的组成可表达为 $\mathrm{TiO}_{1.83} \mathrm{C}_{0.15}$, 主要是由于 $\mathrm{C}$ 进入 $\mathrm{TiO}_{2}$ 薄膜, 置换了其中的 $\mathrm{O}$ 原子, 进而 $\mathrm{C}$ 的 $2 \mathrm{p}$ 轨道与 $\mathrm{O}$ 的 $2 p$ 轨道进行杂化使 $\mathrm{TiO}_{2}$ 禁带宽度减小。 同时 UV-Vis 谱图表明掺杂后的 $\mathrm{TiO}_{2}$ 具有明显的可 见光活性。但对于 $\mathrm{C}$ 原子在 $\mathrm{TiO}_{2}$ 中的掺杂形式有不 同的看法, Sakthivel 等 ${ }^{[9]}$ 以 $\mathrm{TiCl}_{4}$ 和氢氧化四丁基铵 为原料, 通过水解, 陈化, 在 $550^{\circ} \mathrm{C}$ 下焙烧处理得到 $\mathrm{TiO}_{2-x} \mathrm{C}_{x}$, 显示出良好的可见光活性, XPS 及 IR 结果 表明 $\mathrm{C}$ 以碳酸盐的形式存在, 即是 $\mathrm{C}$ 取代了部分 $\mathrm{Ti}$ 阳离子, 而不是碳原子置换了其中的 $\mathrm{O}$ 原子。朱蕾 等 ${ }^{[10]}$ 通过直流反应磁控溅射方法制备了碳掺杂纳 米 $\mathrm{TiO}_{2}$ 薄膜, 由透射光谱曲线计算得到的禁带宽度, 发现适量的碳掺杂使 $\mathrm{TiO}_{2}$ 的禁带宽度由 $3.4 \mathrm{eV}$ 减小 到 $3.1 \mathrm{eV}$ 。李向清等 ${ }^{[11]}$ 以尿素作为碳元素前驱体对 $\mathrm{TiO}_{2}$ 纳米管进行掺杂, 发现碳掺杂 $\mathrm{TiO}_{2}$ 纳米管相对 于未掺杂 $\mathrm{TiO}_{2}$ 纳米管的可见光催化活性明显提高, 可见光照射 $3 \mathrm{~h}$, 罗丹明 B 的降解率可达到 $91 \%$, 比 P25 的降解率提高了约 $62 \%$ 。

目前二氧化钛制备方法主要有阳极氧化法 ${ }^{[12]}$ 、 溶胶-凝胶法 ${ }^{[13]}$ 和水热法 ${ }^{[14]}$ 等。其中阳极氧化法是 以纯钛片为阳极, 石墨为阴极, 在含 $\mathrm{F}^{-}$的溶液中, 在 一定电压下经阳极氧化得到 $\mathrm{TiO}_{2}$ 纳米管阵列薄膜。 纳米管具有较大的比表面积, 较高的光催化氧化活 性和较快的电子传递速度, 有利于提高光催化性 能。本工作采用阳极氧化 $\mathrm{Ti}$ 片( $\mathrm{Ti}$ 丝)法制备出 $\mathrm{TiO}_{2}$ 纳米管电极, 并在热处理过程中加入 $\mathrm{NaHCO}_{3}$ 来制 备 $\mathrm{C}-\mathrm{TiO}_{2}$ 半导体纳米薄膜。

\section{1 实验方法}

\section{1 试剂与仪器}

$\mathrm{Ti}$ 片 ( $\mathrm{Ti}$ 丝) (宝钛集团有限公司); 硝酸(江苏强 盛功能化学股份有限公司); 氢氟酸(江苏肜晟化学 试剂); 硫酸钠(上海大合化学品有限公司)。

使用 Bruker $\mathrm{D} / 8$ 高级衍射仪进行晶型的表征, 以 $\mathrm{Cu}$ 靶 $(40 \mathrm{kV}, 40 \mathrm{~mA})$ 为入射线, 扫描角度范围为 $20^{\circ} \sim 80^{\circ}$ 。采用荷兰 Philips 公司生产的 XL30 扫描电 镜观测样品的形貌，工作电压为 $20 \mathrm{kV}$ 。利用 $\mathrm{X}$ 射 线光电子能谱分析样品表面的各元素相对含量比 例。采用铝靶, 高压 $14.0 \mathrm{kV}$, 功率 $300 \mathrm{~W}$, 通能 $93.9 \mathrm{eV}$, 并以 $\mathrm{C} 1 \mathrm{~s}=284.6 \mathrm{eV}$ 为基准进行结合能校 正。分别采集样品在 $0 \sim 1200 \mathrm{eV}$ 的全扫描谱, 而后 采集各元素相关轨道的窄扫描谱。光电性能测试以 北京畅拓科技有限公司生产的 $500 \mathrm{~W}$ 的短弧氙灯为 光源, 经过石英水槽滤掉红外光得到紫外-可见光, 通过滤光片滤去紫外光 $(<420 \mathrm{~nm})$, 得到可见光, 利 用 CHI660a 化学工作站测试光电流时间曲线。采用 PARSTAT 4000(Princeton Applied Research, 美国)测 试电极的交流阻抗谱 $(100 \mathrm{kHz}-10 \mathrm{mHz}$, 开路电位, $10 \mathrm{mV}$ 微扰)和 Mott-Schottky 曲线(测试电压范围为 $-1 \sim 1.2 \mathrm{~V}$, 频率为 $100 \mathrm{~Hz}$ )。

\section{2 实验过程}

采用阳极氧化法制备 $\mathrm{TiO}_{2}$ 纳米管。将钛片剪成 $3 \mathrm{~cm} \times 9 \mathrm{~cm}$ 大小, 使其尽量平整, 然后在体积比为 5 (去离子水) $: 4\left(\mathrm{HNO}_{3}\right): 1(\mathrm{HF})$ 的抛光液清洗至钛 片表面发亮为止, 再用去离子水冲洗干净。将抛光 后的钛片作为阳极，以石墨作为阴极，取 $250 \mathrm{~mL}$ 的 $0.5 \% \mathrm{HF}$ 水溶液作为电解液放入 $300 \mathrm{~mL}$ 烧杯中, 将烧杯放入冰水浴中，直流稳压电源 $20 \mathrm{~V}$, 打开恒 温磁力摚拌器, 阳极氧化 $40 \mathrm{~min}$, 得到的 $\mathrm{Ti}$ 片用去离 子水反复冲洗。

采用热处理方法制备 $\mathrm{C}-\mathrm{TiO}_{2}$ 纳米管。室温下将 制备好的 $\mathrm{TiO}_{2}$ 纳米管悬空放于盛有适量 $\mathrm{NaHCO}_{3}$ 的小瓷舟上, 放入管式炉中密封, 升温至 $450^{\circ} \mathrm{C}$, 保持 $120 \mathrm{~min}$ 。在热处理过程中, $\mathrm{NaHCO}_{3}$ 分解产生 $\mathrm{CO}_{2}$, 在 $\mathrm{CO}_{2}$ 气氛中得到碳掺杂二氧化钛纳米管阵 列薄膜, 标记为 $\mathrm{C}-\mathrm{TiO}_{2}$ 。与不加 $\mathrm{NaHCO}_{3}$ 直接热处 理得到 $\mathrm{TiO}_{2}$ 作为对比。

染料敏化太阳能电池的制备过程如下：利用阳 极氧化 $\mathrm{Ti}$ 丝的方法制备丝状 $\mathrm{Ti} / \mathrm{TiO}_{2}$, 利用相同的方 
法制备未掺杂和碳掺杂的 $\mathrm{Ti} / \mathrm{TiO}_{2}$ 丝。待 $\mathrm{TiO}_{2}$ 丝冷 却至室温后, 用 $0.2 \mathrm{~mol} / \mathrm{L}$ 的 $\mathrm{TiCl}_{4}$ 在 $60^{\circ} \mathrm{C}$ 下水浴处 理 $1 \mathrm{~h}$, 然后在 $450^{\circ} \mathrm{C}$ 下热处理 $30 \mathrm{~min}$, 自然冷却至 $80^{\circ} \mathrm{C}$, 放入 $0.5 \mathrm{mmol} / \mathrm{L} \mathrm{N} 719$ 染料的无水乙醇溶液 中敏化 $12 \mathrm{~h}$, 即可得到染料敏化的丝状 $\mathrm{TiO}_{2}$ 纳米 管光阳极。将得到的染料敏化 $\mathrm{TiO}_{2}$ 纳米管薄膜丝状 光阳极和铂丝 $(\phi 0.5 \mathrm{~mm})$ 对电极放入毛细玻璃管中, 然后利用绝缘胶将两端密封。注入含有 $0.1 \mathrm{~mol} / \mathrm{L}$ 的 $\mathrm{LiI}, 0.05 \mathrm{~mol} / \mathrm{L}$ 的 $\mathrm{I}_{2}$ 和 $0.5 \mathrm{~mol} / \mathrm{L}$ 的 4-叔丁基吡啶, $0.1 \mathrm{~mol} / \mathrm{L}$ 的 $\mathrm{N}$-甲基苯并咪唑, $0.1 \mathrm{~mol} / \mathrm{L}$ 的硫氰酸 胍的 3-甲基丙腈溶液, 就可以得到立体采光结构 的 $\mathrm{TiO}_{2}$ 纳米管薄膜针状光阳极的染料敏化太阳能 电池 ${ }^{[15]}$ 。

\section{2 结果与讨论}

\subsection{SEM 分析}

图 1 是 $\mathrm{TiO}_{2}(\mathrm{a})$ 和 $\mathrm{C}-\mathrm{TiO}_{2}(\mathrm{~b})$ 纳米管薄膜的 SEM 照片, 从图中可以看到, 在 $\mathrm{Ti}$ 片上生长了一层孔排列 规则的纳米管，管径约 $100 \mathrm{~nm}$ ，与文献报道相符合 ${ }^{[10]}$, $\mathrm{C}-\mathrm{TiO}_{2}$ 纳米管也具有较好的规则性, 呈现出纳米管 的特征形貌, 这为光生电子提供了传输通道, 并且 延长了光生电子的寿命, 可以看出 $\mathrm{C}$ 掺杂不影响 $\mathrm{TiO}_{2}$ 纳米管的形貌。

\subsection{XRD 分析}

图 2 为 $\mathrm{TiO}_{2}$ 纳米薄膜的 XRD 图谱, 图谱中存 在明显的 $\mathrm{Ti}$ 特征衍射峰, 这来源于 $\mathrm{Ti}$ 基底。图 2(a) 中可以看到锐钛矿型 $\mathrm{TiO}_{2}$ 的特征衍射峰, 说明阳极 氧化制备的 $\mathrm{TiO}_{2}$ 纳米管经 $450^{\circ} \mathrm{C}$ 热处理 $120 \mathrm{~min}$ 后 形成了锐钛矿型的 $\mathrm{TiO}_{2}$ 。图 2(b) 是经过 $\mathrm{NaHCO}_{3}$ 处 理得到的纳米薄膜, 从图中可以看出, $\mathrm{C}-\mathrm{TiO}_{2}$ 纳米 薄膜也形成了锐钛矿型的 $\mathrm{TiO}_{2}$, 在 $25.3^{\circ}$ 处锐钛矿 型 $\mathrm{TiO}_{2}$ 的衍射峰强度增强, 强度是未掺杂的 1.25 倍, 表明锐钛矿型 $\mathrm{TiO}_{2}$ 晶相增多, 结晶程度更高 ${ }^{[16]}$, 较 高的结晶度有利于内部载流子的传输, 促进电子空穴的分离 ${ }^{[17]}$ 。
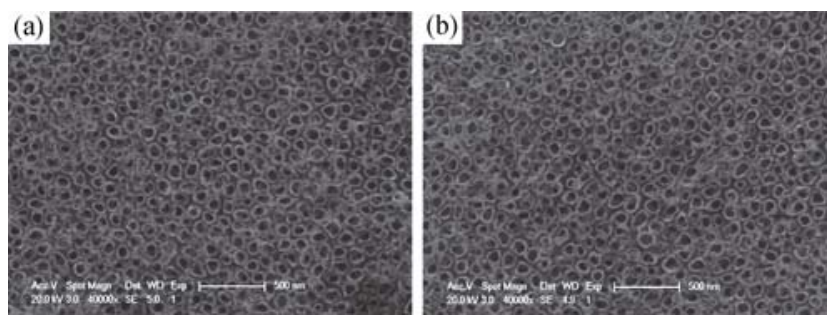

图 $1 \mathrm{TiO}_{2}$ 纳米管 (a) and C- $\mathrm{TiO}_{2}$ 纳米管(b)的 SEM 照片 Fig. 1 SEM images of $\mathrm{TiO}_{2}$ (a) and $\mathrm{C}-\mathrm{TiO}_{2}$ nanotubes (b)

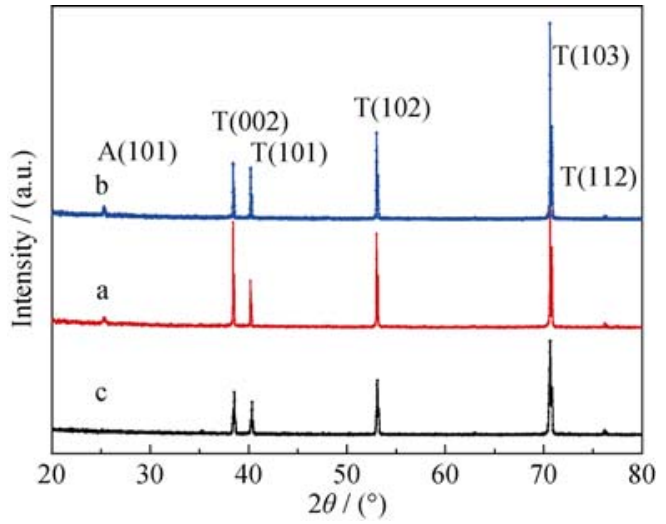

图 $2 \mathrm{TiO}_{2}(\mathrm{a})$ 和 $\mathrm{C}-\mathrm{TiO}_{2}(\mathrm{~b})$ 和 $\mathrm{Ti}$ 基底(c)的 XRD 图谱

Fig. 2 XRD patterns of $\mathrm{TiO}_{2}$ (a), C-TiO $(\mathrm{b})$ and titanium substrate (c)

\subsection{XPS 成分分析}

图 3 是 $\mathrm{C}-\mathrm{TiO}_{2}(\mathrm{~b})$ 和 $\mathrm{TiO}_{2}(\mathrm{a})$ 纳米管的 XPS 图谱。 从图 $3 \mathrm{~A}$ 中可以看出, $\mathrm{C}^{-} \mathrm{TiO}_{2}$ 纳米管的 $\mathrm{O} 1 \mathrm{~s}$ 峰位于 $529.8 \mathrm{eV}, \mathrm{Ti} 2 \mathrm{p}$ 峰位于 458.5 和 $464.2 \mathrm{eV}$, Ti2s 峰位 于 $565.5 \mathrm{eV}, \mathrm{C} 1 \mathrm{~s}$ 峰出现在 $284.6 \mathrm{eV}$, 说明样品中含 有 $\mathrm{C} 、 \mathrm{Ti}$ 和 $\mathrm{O}$ 三种元素。

图 3B 是 $\mathrm{C}-\mathrm{TiO}_{2}(\mathrm{~b})$ 和 $\mathrm{TiO}_{2}(\mathrm{a})$ 纳米管的纳米管薄 膜的 $\mathrm{C} 1 \mathrm{~s}$ 特征峰, 从图中可以观察到三个位于 284.6、286.4、288.2 eV 的峰，根据文献[18]，位于 $284.6 \mathrm{eV}$ 的峰主要来自于样品表面的固溶态 C 污染, 而位于 286.4 和 $288.2 \mathrm{eV}$ 的特征峰分别属于 $\mathrm{C}-\mathrm{O}$ 键 和 $\mathrm{C}=\mathrm{O}$ 键, 主要由表面吸附的杂质引起的 ${ }^{[19]}$ 。

图 3C 是 $\mathrm{C}-\mathrm{TiO}_{2}(\mathrm{~b})$ 和 $\mathrm{TiO}_{2}(\mathrm{a})$ 纳米管薄膜的 $\mathrm{Ti} 2 \mathrm{p}$ 特征峰, 其中 $\mathrm{Ti} 2 \mathrm{p} 3 / 2$ 特征峰位于 $458.4 \mathrm{eV}$, 纯 $\mathrm{TiO}_{2}$ 的 Ti2p 特征峰应该位于 $458.9 \mathrm{eV}$ ，与特征峰位置吻 合，说明碳掺杂 $\mathrm{TiO}_{2}$ 以后，样品的主要产物仍是 $\mathrm{TiO}_{2}$ 。 另外, 可以看到样品的 Ti2p3/2 特征峰为 $458.4 \mathrm{eV}$, 相 对于纯 $\mathrm{TiO}_{2}$ 的 $\mathrm{Ti} 2 \mathrm{p}$ 特征峰向低能方向移动，这说明 样品中存在 $\mathrm{Ti}-\mathrm{C}$ 键, 在 $\mathrm{Ti}-\mathrm{C}$ 键的共价作用下, $\mathrm{Ti}$ 原 子周围的电子结构得到了的修饰。

图 3D 是 $\mathrm{C}-\mathrm{TiO}_{2}(\mathrm{~b})$ 和 $\mathrm{TiO}_{2}(\mathrm{a})$ 纳米管薄膜的 $\mathrm{O} 1 \mathrm{~s}$ 特征峰, 主峰能量位于 $529.8 \mathrm{eV}$ 左右, 对应于 $\mathrm{TiO}_{2}$ 中晶格的能量位置, 在主峰右侧高能位置又有一拓 展峰，位于 $531.8 \mathrm{eV}$, 该峰对应于 $\mathrm{C}$ 原子替代了 $\mathrm{TiO}_{2}$ 中 $\mathrm{O}$ 原子后 $\mathrm{O}-\mathrm{Ti}-\mathrm{C}$ 键的能量位置 ${ }^{[20]}$, 该峰的出现同 样表明 $\mathrm{C}$ 原子在 $\mathrm{TiO}_{2}$ 晶格中是替代型掺杂。

\section{4 样品的紫外-可见漫反射光谱}

图 4 为 $\mathrm{TiO}_{2}$ 和 $\mathrm{C}-\mathrm{TiO}_{2}$ 纳米薄膜电极的紫外-可 见漫反射光谱图。从图中可以看出, $\mathrm{C}-\mathrm{TiO}_{2}$ 纳米薄 膜相对于 $\mathrm{TiO}_{2}$ 纳米薄膜在紫外和可见区域都有较 大的吸收, 并且吸收带边红移, 与 $\mathrm{TiO}_{2}$ 相比, $\mathrm{C}-\mathrm{TiO}_{2}$ 的禁带宽度变窄, 可以提高对太阳光的利用 率, 预示着 $\mathrm{C}-\mathrm{TiO}_{2}$ 具有更好的光电催化活性。 

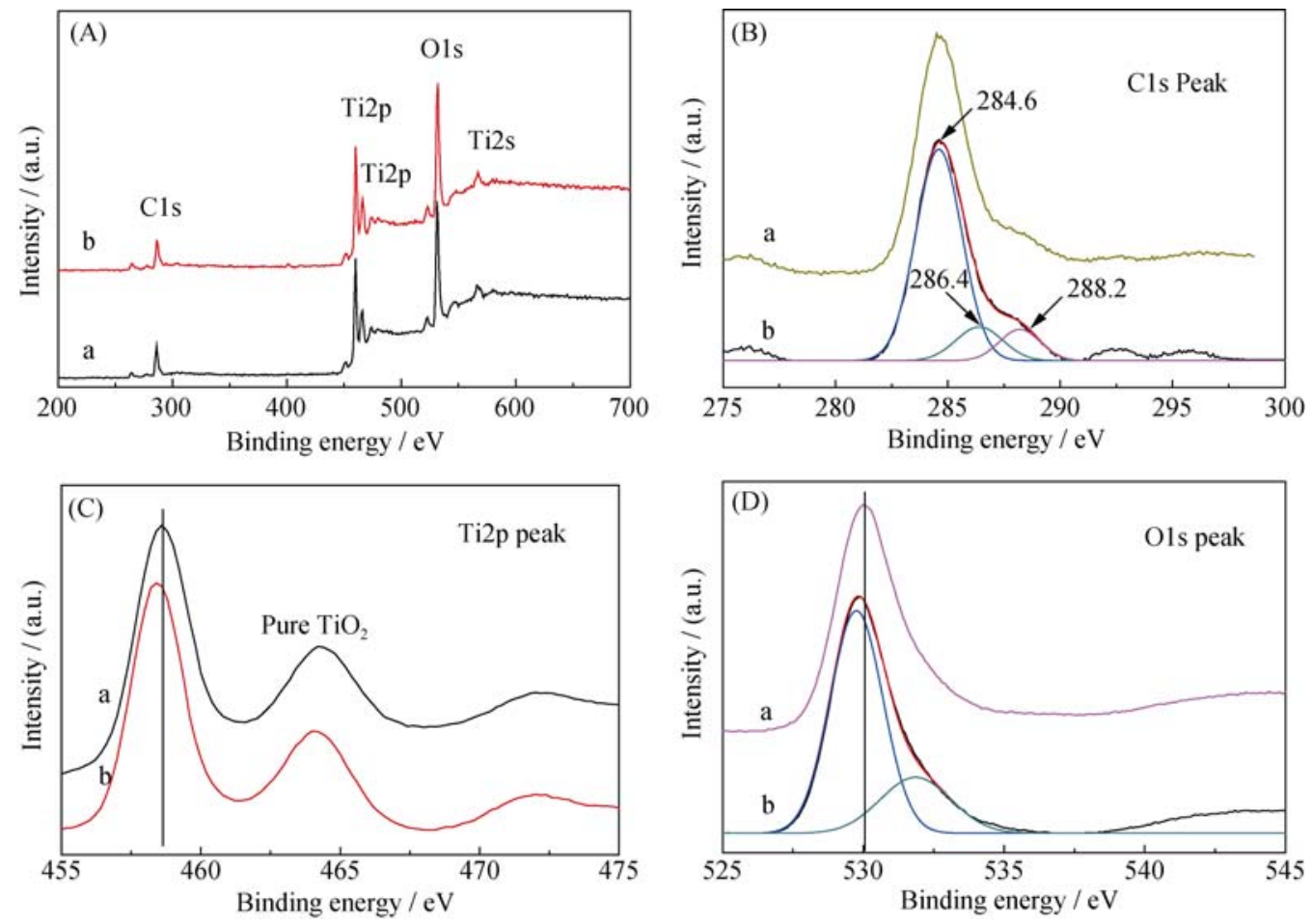

图 $3 \mathrm{TiO}_{2}$ (a)及 $\mathrm{C}-\mathrm{TiO}_{2}(\mathrm{~b})$ 纳米管的 XPS 分析结果

Fig. 3 XPS spectra of $\mathrm{TiO}_{2}$ (a) and $\mathrm{C}-\mathrm{TiO}_{2}(\mathrm{~b})$

The full-scale XPS spectra (A); high resolution XPS spectra of Cls (B), Ti2p (C), Ols(D)

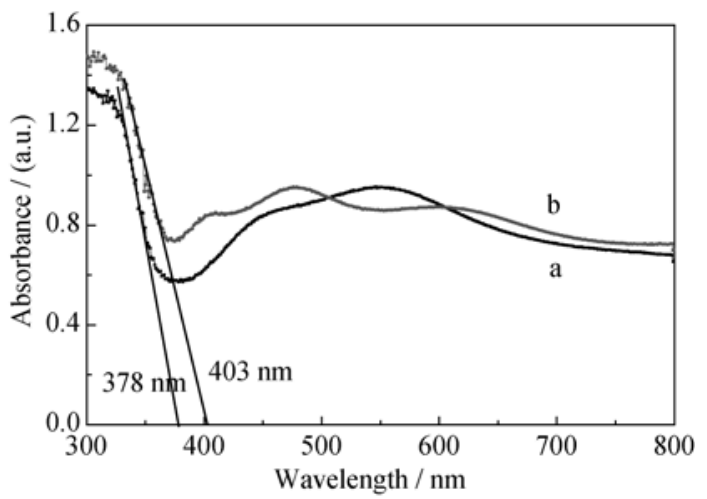

图 $4 \mathrm{TiO}_{2}$ (a)和 C- $\mathrm{TiO}_{2}$ (b)纳米管的 UV-Vis 漫反射光谱图

Fig. 4 UV-Vis diffuse reflectance spectra of $\mathrm{TiO}_{2}$ (a) and $\mathrm{C}-\mathrm{TiO}_{2}$ (b) nanotube

\subsection{EIS 谱和 Mott-Schottky 分析}

图 5 分别为 $450^{\circ} \mathrm{C}$ 热处理 $120 \mathrm{~min}$ 得到的 $\mathrm{TiO}_{2}$ (a) 和 $\mathrm{C}-\mathrm{TiO}_{2}$ (b) 纳米薄膜电极的 EIS 曲线 Nyquist 图(A)和 Bode 图(B)。测试在无光照、室温 下进行。从图 $5 \mathrm{~A}$ 中可以看出: $\mathrm{C}-\mathrm{TiO}_{2}$ 纳米薄膜电极 的阻抗圆弧半径小于 $\mathrm{TiO}_{2}$ 纳米薄膜电极。同时从图 5(B)中可以看出在相同频率条件下, $\mathrm{C}-\mathrm{TiO}_{2}$ 纳米薄 膜电极的阻抗小于 $\mathrm{TiO}_{2}$ 纳米薄膜电极。不同电极 EIS 图上的圆弧半径相对大小同相应 $\mathrm{TiO}_{2}$ 薄膜电极 的光催化反应速率的相对大小相反 ${ }^{[21]}$, 即阻抗谱圆 弧半径越小, 阻抗值越小, 光催化反应进行得越快。 因此 $\mathrm{C}$ 掺杂可提高 $\mathrm{TiO}_{2}$ 薄膜电极的光催化活性。
对 $\mathrm{TiO}_{2}$ 和 $\mathrm{C}-\mathrm{TiO}_{2}$ 纳米薄膜电极进行了 MottSchottky 测试, 测试结果如图 6 所示, 根据 MottSchottky 关系式:

$$
\frac{1}{C^{2}}=\frac{2}{\varepsilon \varepsilon_{0} \mathrm{e} N_{\mathrm{D}}}\left(E-E_{\mathrm{fb}}-\frac{\mathrm{k} T}{\mathrm{e}}\right)
$$

其中为 $\varepsilon$ 介电常数, 本文取 $80 \mathrm{~F} / \mathrm{m}^{[22]}, \varepsilon_{0}$ 为真空介电 常数, 其值为 $8.85 \times 10^{-12} \mathrm{~F} / \mathrm{m}$; e 为电子电荷数, $1.6 \times$ $10^{-19} \mathrm{C} ; T$ 为绝对温度; $\mathrm{k}$ 为波尔兹曼常数, $1.38 \times$ $10^{-23} \mathrm{~J} / \mathrm{K}, E_{\mathrm{fb}}$ 为半导体平带电位, $N_{\mathrm{D}}$ 为半导体载流子 浓度。室温下 $\mathrm{k} T / \mathrm{e}$ 可忽略不计。

图 6 为 $\mathrm{TiO}_{2}(\mathrm{a})$ 和 $\mathrm{C}-\mathrm{TiO}_{2}(\mathrm{~b})$ 纳米薄膜电极在 $0.5 \mathrm{~mol} / \mathrm{L} \mathrm{Na}_{2} \mathrm{SO}_{4}$ 溶液中的 Mott-Schottky 曲线。根据 直线部分的截距，可以得出 $\mathrm{TiO}_{2}$ 和 $\mathrm{C}-\mathrm{TiO}_{2}$ 纳米薄膜 电极平带电位分别是 $-0.28 \mathrm{~V}$ 和 $-0.38 \mathrm{~V}$, 说明碳掺杂 对 $\mathrm{TiO}_{2}$ 的费米能级有较大的影响, 相对于 $\mathrm{TiO}_{2}$ 薄膜, $\mathrm{C}-\mathrm{TiO}_{2}$ 薄膜的费米能级位置负移, 光生电子的还原 能力增强 ${ }^{[23]}$ 。 $\mathrm{TiO}_{2}$ 和 $\mathrm{C}-\mathrm{TiO}_{2}$ 纳米薄膜电极载流子浓 度分别是 $8.2 \times 10^{33}$ 和 $1.2 \times 10^{34} \mathrm{~m}^{-3}, \mathrm{C}-\mathrm{TiO}_{2}$ 纳米管薄 膜具有更高的载流子浓度。更负的平带电位以及更 高的载流子浓度, 有利于光电化学性能的提高 ${ }^{[24]}$ 。

\section{6 光电化学测试}

图 7 是 $\mathrm{TiO}_{2}(\mathrm{a})$ 和 $\mathrm{C}-\mathrm{TiO}_{2}(\mathrm{~b})$ 纳米薄膜电极在紫 外-可见光 $(A)$ 及可见光 $(B)$ 照射下的瞬时光电流曲 线, 从图中可以看出, $\mathrm{TiO}_{2}$ 纳米薄膜电极和 $\mathrm{C}-\mathrm{TiO}_{2}$ 

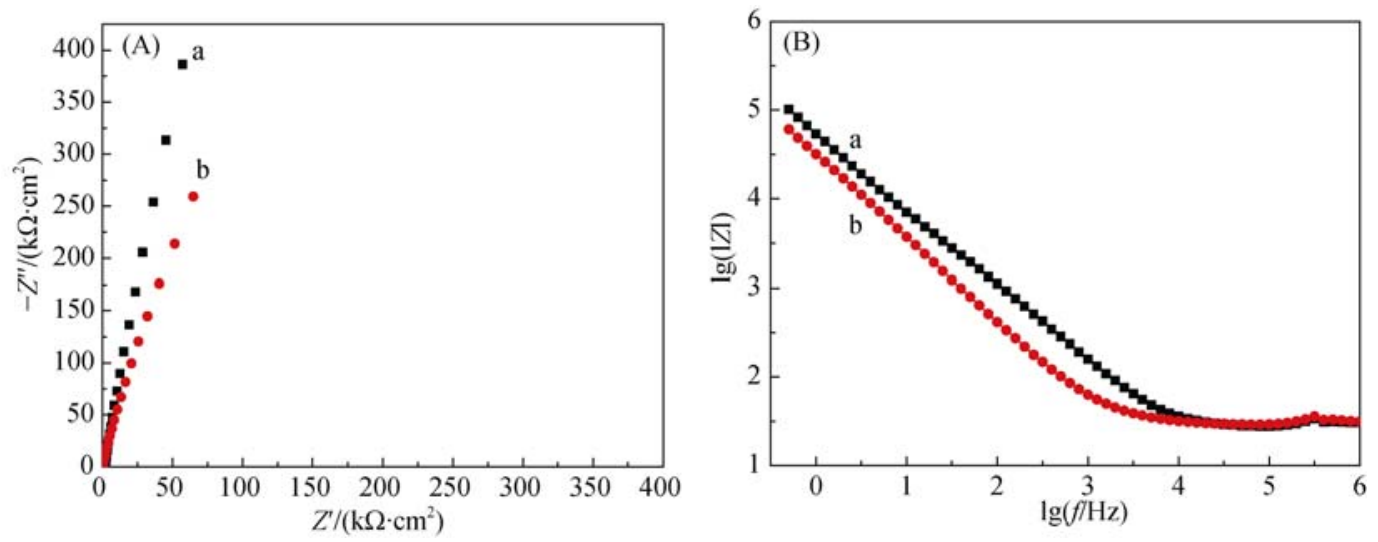

图 $5 \mathrm{TiO}_{2}(\mathrm{a})$ 和 $\mathrm{C}-\mathrm{TiO}_{2}$ (b)薄膜电极在开路电压下的 EIS 的 Nyquist(A) 和 Bode 曲线(B)

Fig. 5 EIS Nyquist (A) and Bode (B) plots for $\mathrm{TiO}_{2}$ (a) and $\mathrm{C}-\mathrm{TiO}_{2}$ (b) thin film electrodes at open circuit potential

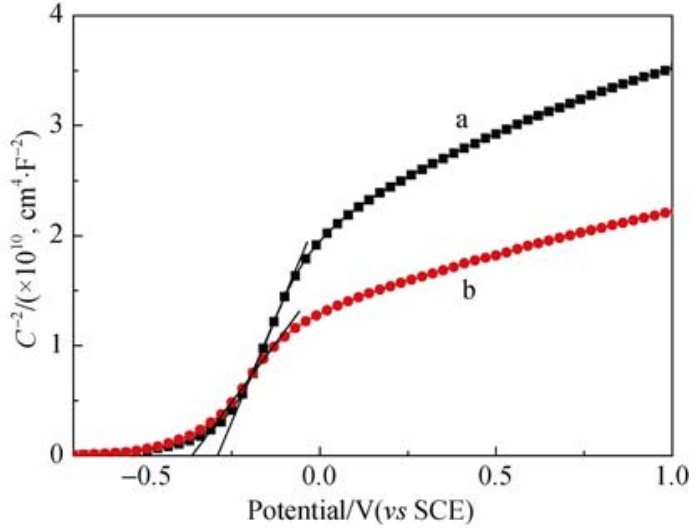

图 $6 \mathrm{TiO}_{2}$ (a) 和 $\mathrm{C}-\mathrm{TiO}_{2}$ (b)纳米管电极的 Mott-Schottky 曲线 Fig. 6 Mott-Schottky plots for $\mathrm{TiO}_{2}$ (a) and C-TiO 2 (b) nanotube electrodes

纳米薄膜电极在紫外-可见光的照射下光电流强度 分别为 75.86、131.55 $\mu \mathrm{A} / \mathrm{cm}^{2}, \mathrm{C}-\mathrm{TiO}_{2}$ 纳米薄膜电极 具有更强的光电流, 光电流强度是未掺杂 $\mathrm{TiO}_{2}$ 的 1.73 倍。图 7(B)显示了 $\mathrm{TiO}_{2}(\mathrm{a})$ 和 $\mathrm{C}-\mathrm{TiO}_{2}(\mathrm{~b})$ 在可见
光照射下的瞬时光电流曲线，从图中可以看出， $\mathrm{TiO}_{2}$ 纳米薄膜电极和 $\mathrm{C}-\mathrm{TiO}_{2}$ 纳米薄膜电极在可见 光照射下光电流强度分别为 $0.42 、 0.50 \mu \mathrm{A} / \mathrm{cm}^{2}$, $\mathrm{C}-\mathrm{TiO}_{2}$ 纳米薄膜电极具有更强的光电流, 光电流强 度是未掺杂 $\mathrm{TiO}_{2}$ 的 1.20 倍。

\section{7 针状染料敏化太阳能电池的 $J-V$ 曲线}

利用 $\mathrm{TiO}_{2}$ 和 $\mathrm{C}-\mathrm{TiO}_{2}$ 丝状光阳极和 $\mathrm{Pt}$ 丝对电极组 装了染料敏化太阳能电池, 并在 AM1.5 $100 \mathrm{~mW} / \mathrm{cm}^{2}$ 标准光照条件下, 测量了电池的 $J-V$ 曲线(图 8 )。表 1 是染料敏化太阳能电池的性能参数。从图 8 可以 看出, 利用阳极氧化的 $\mathrm{TiO}_{2}$ 和 $\mathrm{Pt}$ 丝对电极组装的染 料敏化太阳能电池的短路电流密度和电池效率分别 为 $0.078 \mathrm{~mA} / \mathrm{cm}^{2}$ 和 $1.4 \%$; 利用 $\mathrm{NaHCO}_{3}$ 处理得到碳 掺杂后的 $\mathrm{C}-\mathrm{TiO}_{2}$ 和 $\mathrm{Pt}$ 丝对电极组装的染料敏化太阳 能电池短路电流密度和电池效率分别为 $0.17 \mathrm{~mA} / \mathrm{cm}^{2}$ 和 3.8\%, 短路电流密度和电池效率均有所提高, 说 明适量的碳掺杂有利于提高电池效率(表 1)。
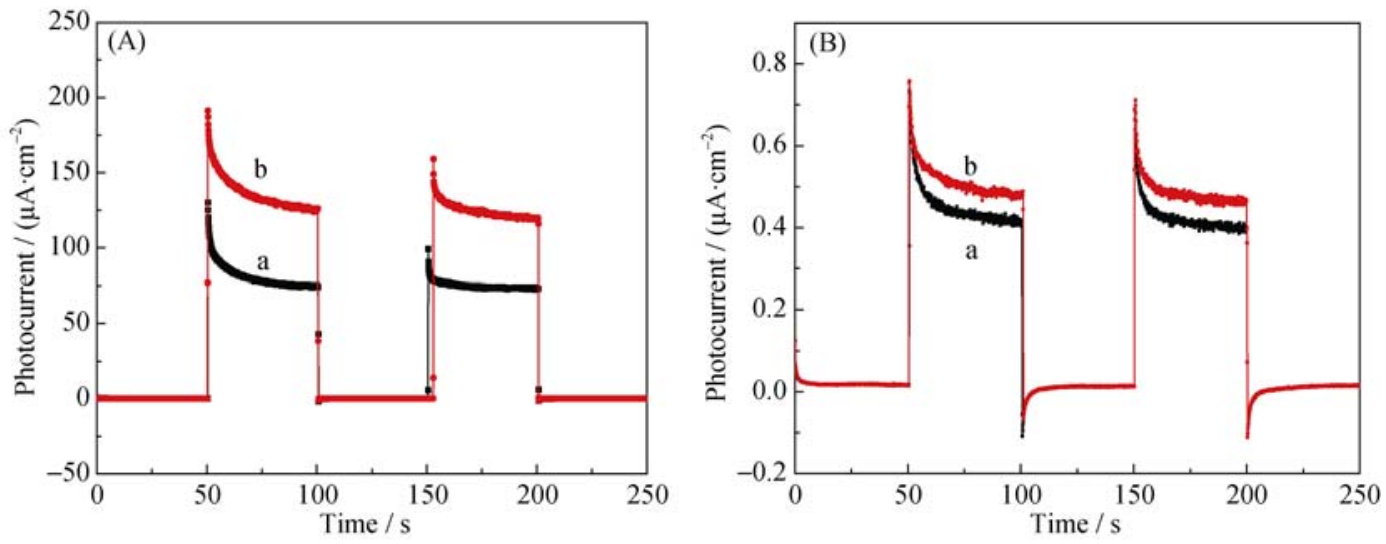

图 $7 \mathrm{TiO}_{2}(\mathrm{a})$ 和 $\mathrm{C}-\mathrm{TiO}_{2}(\mathrm{~b})$ 在紫外-可见光(A)和可见光(B)下的光电流曲线

Fig. 7 Photocurrent-transient curves of $\mathrm{TiO}_{2}$ (a) and $\mathrm{C}-\mathrm{TiO}_{2}$ (b) electrodes under UV-Vis (A) and visible light (B) illumination 


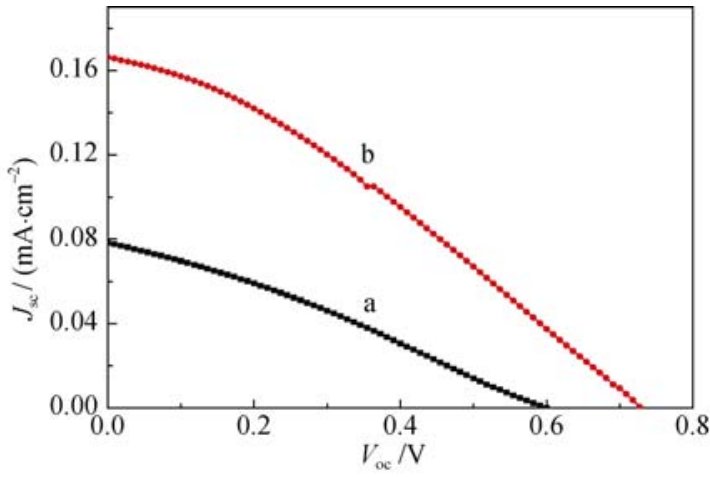

图 $8 \mathrm{TiO}_{2}(\mathrm{a})$ 和 $\mathrm{C}-\mathrm{TiO}_{2}(\mathrm{~b})$ 针状光电池的光电流密度和光电压 关系曲线

Fig. 8 Photocurrent density-photovoltage $(J-V)$ curves for needle-shaped DSSCs of $\mathrm{TiO}_{2}$ (a) and $\mathrm{C}-\mathrm{TiO}_{2}$ (b) thin film electrodes

表 $1 \mathrm{TiO}_{2}$ (a)和 $\mathrm{C}-\mathrm{TiO}_{2}$ (b) 针状光电池的光伏性能参数

Table1 Photovoltaic performances for needle-shaped DSSCs of $\mathrm{TiO}_{2}$ and $\mathrm{C}-\mathrm{TiO}_{2}$ thin film electrodes

\begin{tabular}{ccccc}
\hline Cell & $V_{\text {oc }} / \mathrm{V}$ & $J_{\text {sc }} /\left(\mathrm{mA} \cdot \mathrm{cm}^{-2}\right)$ & $F F$ & $\eta / \%$ \\
\hline $\mathrm{TiO}_{2}$ & 0.60 & 0.08 & 0.29 & $1.38 \%$ \\
$\mathrm{C}-\mathrm{TiO}_{2}$ & 0.72 & 0.17 & 0.32 & $3.82 \%$ \\
\hline
\end{tabular}

\section{3 结论}

利用 $\mathrm{NaHCO}_{3}$ 热分解生成的 $\mathrm{CO}_{2}$ 一步热处理制 备了具有光电响应特性的 $\mathrm{C}-\mathrm{TiO}_{2}$ 半导体。结果表明: $\mathrm{C}-\mathrm{TiO}_{2}$ 纳米薄膜电极在紫外-可见光和可见光区域 都有较大吸收, 并且吸收带从 $\mathrm{TiO}_{2}$ 电极的 $360 \mathrm{~nm}$ 红移到 $\mathrm{C}-\mathrm{TiO}_{2} 380 \mathrm{~nm}$, 平带电位从- $0.28 \mathrm{~V}$ 负移到 $-0.38 \mathrm{~V}, \mathrm{C}-\mathrm{TiO}_{2}$ 纳米薄膜在紫外一可见光下的光电 流强度是未掺杂 $\mathrm{TiO}_{2}$ 的 1.73 倍, 在可见光下是未掺 杂 $\mathrm{TiO}_{2}$ 的 1.20 倍。实验发现, 经过 $\mathrm{NaHCO}_{3}$ 处理后, 利用 $\mathrm{Ti}$ 制作染料敏化太阳能电池的效率提高。该方 法操作简便, 无毒, 环保, 有望在染料敏化太阳能 电池领域得到应用。

\section{参考文献:}

[1] LIU ZHAO-YUE, MISRA MANO. Dye-sensitized photovoltaic wires using highly ordered $\mathrm{TiO}_{2}$ nanotube arrays. ACS Nano, 2010, 4(4): 2196-2200.

[2] AHMED M A, EL-KATORI EMAD E, GHARNI ZARHA H. Photocatalytic degradation of methylene blue dye using $\mathrm{Fe}_{2} \mathrm{O}_{3}$ / $\mathrm{TiO}_{2}$ nanoparticles prepared by Sol-Gel method. J. Alloys Compd., 2013, 553: 19-29.

[3] CHEN QI-FENG, SHI WEI-MEI, JIANG DONG, et al. Visiblelight-activated Ni-Si co-doped $\mathrm{TiO}_{2}$ with photocatalytic performance. Acta Chimica Sinica, 2010, 68(4): 301-308.

[4] CUI XIAO-LI, GU HAI-JIE, LU JUN, et al. Nanostructured carbon-doping anodic $\mathrm{TiO}_{2}$ from $\mathrm{TiC}$ and Its photoelectrochemical properties. Nanosci. Nanotechnol., 2007, 7(9): 3140-3145.

[5] LI HAI-YAN, WANG DE-JUN, FAN HAI-MEI, et al. Synthesis of highly efficient C-doped $\mathrm{TiO}_{2}$ photocatalyst and its photo- generated charge-transfer properties. Colloid Interface Sci., 2011, 354: 175-180.

[6] LI YAN-HONGCAO WEN-BIN,WEI YI, et al. Preparation of nitrogendoped nano- $\mathrm{TiO}_{2}$ powders. Journal of Inorganic Materials, 2006, 21(5): 1067-1072.

[7] SUN MING-XUAN, SONG PENG, LI JING, et al. Preparation, characterization and applications of novel carbon and nitrogen codoped $\mathrm{TiO}_{2}$ nanoparticles from annealing TiN under $\mathrm{CO}$ atmosphere. Mater. Res. Bull., 2013, 48(10): 4271-4276.

[8] KHAN SHAHED U M, AL-SHAHRY MOFAREH, INGLER WILLIAM B. Efficient photochemical water splitting by a chemically modified n- $\mathrm{TiO}_{2}$. Science, 2002, 297(5590): 2243-2245.

[9] SAKTHIVELS, KISCH HORST. Daylight photoeatalysis by carbon-modified titanium dioxide. Angew. Chem. Int. Ed., 2003, 42(40): 4908-4911.

[10] ZHU LEI, CUI XIAO-LI, SHEN JIE, et al. Visible Light Photoelectrochemical response of carbon-doped $\mathrm{TiO}_{2}$ thin films prepared by DC reactive magnetron sputtering. Acta Physico-Chimica Sinica, 2007, 23(11): 1662-1666.

[11] LI XIANG-QING, KANG SHI-ZHAO, TANG YUN-QIU, et al. Preparation and visible light photocatalytic activity of carbon doped titanium dioxide nanotubes. Chinese Journal of Applied Chemistry, 2013, 30(2): 178-184.

[12] BABU K FIROZ, MARXE K, KULANDAINTHAN M ANBU. Anodically fabricated $\mathrm{TiO}_{2}$ nanopores for electrocatalytic reduction of aldehydes. J. Electroanal. Chem., 2011, 663(2): 79-83.

[13] LIN XIAO-XIA, JI XIANG, FU DE-GANG, et al. Photocatalytic properties of magnetic activated carbon supported F-doped $\mathrm{TiO}_{2}$. Journal of Inorganic Materials, 2013, 28(9): 997-1002.

[14] WU JIN- MING, SONG XIAO-MEI, YAN MI. Alkaline hydrothermal synthesis of homogeneous titania microspheres with urchin-like nanoarchitectures for dye effluent treatments. J. Hazard. Mater., 2011, 194: 338-344.

[15] SUN MING-XUAN, CUI XIAO-LI. Needle-shaped 3D dye-sensitized solar cells using anodized Ti wire and Pt nanoparticles/carbon fiber electrodes. J. Power Sources, 2013, 223: 74-78.

[16] LIN XIAO-XIA, RONG FEI, JI XIANG, et al. Carbon-doped mesoporous $\mathrm{TiO}_{2}$ film and its photocatalytic activity. Microporous Mesoporous Mater., 2011, 142(1): 276-281.

[17] SHEN JING-JING, LIU CHANG, ZHU YU-DAN, et al. Photocatalytic properties of mesoporous $\mathrm{TiO}_{2}$ prepared by hydrothermal method. Acta Physico-Chimica Sinica, 2009, 25(5): 1013-1018.

[18] SHI Z M, YE X Y, LIANG K M, et al. XPS analysis of light elements $(\mathrm{C}, \mathrm{N})$ remaining in Sol-Gel derived $\mathrm{TiO}_{2}$ films. Mater. Sci. Lett., 2003, 22(18): 1255-1258.

[19] CHU DAO-BAO, YUAN XI-MEI, QIN GUO-XU, et al. Efficient carbon-doped nanostructured $\mathrm{TiO}_{2}$ (anatase) film for photoelectrochemical solar cells. J. Nanopart.Res., 2008, 10(2): 357-363.

[20] SANTERRE F, EL KHAKANI M A, CHAKER M, et al. Properties of TiC thin films grown by pulsed laser deposition. Appl. surf. sci., 1999, 148(1/2): 24-33.

[21] HUO LI, DING KE-QIANG, WANG QING-FEI, et al. Electrochemistry studies on $\mathrm{Fe}^{3+}$ doped $\mathrm{TiO}_{2}$ films electrode. Nanomaterial and Structure, 2005, 42(2): 69-77.

[22] GAO JIA-CHENG, XIE FENG-YU, ZHANG MIN. Influence of heat treatment on the photoelectron-chemical performance of $\mathrm{Zn}^{2+}$-doping $\mathrm{TiO}_{2}$. Journal of Functional Materials, 2013, 44(6): 826-830.

[23] WANG BAO-HUI, WANG DE-JUN, LI TIE-JIN. Studies on photoelectrochemical properties of porous silicon. Chemical Journal of Chinese Universities, 1997, 18(4): 621-624.

[24] SUN MING-XUAN, CUI XIAO-LI. Anodically grown Si-W codoped $\mathrm{TiO}_{2}$ nanotubes and its enhanced visible light photoelectrochemical response. Electrochem. Commun., 2012, 20: 133-136. 